\title{
Travel Time Model for Right-Turning Vehicles of Secondary Street at Unsignalized Intersections
}

\author{
Feng Yu-Qin, ${ }^{1}$ Leng Jun-Qiang, ${ }^{2,3}$ Wang Peng, ${ }^{4} \mathrm{He} \mathrm{Yi}^{3}{ }^{3}$ and Zhang Gui-e ${ }^{3}$ \\ ${ }^{1}$ School of Automobile and Traffic Engineering, Heilongjiang Institute of Technology, Harbin 150050, China \\ ${ }^{2}$ School of Management, Harbin Institute of Technology, Harbin 150001, China \\ ${ }^{3}$ School of Automobile Engineering, Harbin Institute of Technology, Weihai 264209, China \\ ${ }^{4}$ Representative Office of PLA in Harbin Railway Administration, Harbin 150001, China
}

Correspondence should be addressed to Leng Jun-Qiang; lengjunq@tom.com

Received 8 November 2012; Revised 9 February 2013; Accepted 17 February 2013

Academic Editor: Wuquan Li

Copyright (C) 2013 Feng Yu-Qin et al. This is an open access article distributed under the Creative Commons Attribution License, which permits unrestricted use, distribution, and reproduction in any medium, provided the original work is properly cited.

\begin{abstract}
The travel time of right-turning vehicles on secondary street at unsignalized intersection is discussed in this paper. Under the assumption that the major-street through vehicles' headway follows Erlang distribution and secondary-street right-turning vehicles' headway follows Poisson distribution. The right-turning vehicles travel time model is established on the basis of gap theory and M/G/1 queue theory. Comparison is done with the common model based on the assumption that the major-street vehicles' headway follows Poisson distribution. An intersection is selected to verify each model. The results show that the model established in this paper has stronger applicability, and its most relative error is less than $15 \%$. In addition, the sensitivity analysis has been done. The results show that right-turning flow rate and major-street flow rate have a significant impact on the travel time. Hence, the methodology for travel time of right-turning vehicles at unsignalized intersection proposed in this paper is effective and applicable.
\end{abstract}

\section{Introduction}

As a bottleneck of urban road network, intersections are the emphasis in traffic management and control [1-3]. The travel time of vehicles at intersections is the basis to evaluate road traffic efficiency and the Intelligent Traffic System (ITS) applications. It is also one of the breakthrough points to calculate the vehicles delay at intersections $[4,5]$. Based on the analysis of the conflict disciplines of the four-phase signalized intersection between right-turning vehicles and straightgoing bicycles, Liang et al. established a theoretical model and a binary regression model of right-turning vehicles travel time. The former was based on gap theory and queue theory, and the latter was established on the basis of field observation data. In the binary regression model, it takes right-turning vehicles flow rate and bicycle through flow rate as independent variables. Meanwhile, their application conditions were studied, respectively [6]. Smith and Walsh established motor vehicles and nonmotor vehicles delay models under different mixed traffic conditions and traffic control methods [7]. Liu et al. took the basic link travel time and intersection delay as the basic unit of vehicle travel time in urban road network [8]. Ban et al. believed that vehicle travel time at signalized intersections contained discontinuities and nonsmoothness, and intersection delay pattern can be used to estimate realtime queue length at intersection [9]. Ahmed studied the travel time of indirect right-turning vehicles at intersection with a GPS device [10]. Lu et al. established the model of travel time at intersection with microscopic simulation data. The model considered the signal control effect at a variety of traffic volume combinations [11].

As mentioned above, there are more studies about vehicles delay at intersections, while few researches are about travel time of different turning movements at intersections [12-15]. Typically, Liang et al. established a right-turning motor vehicles' travel time model with the consideration of conflicts between motor vehicles and nonmotor vehicles at signalized intersections, and it provides a good reference for the following researches. The model was built on strict assumptions. For instance, nonmotor flow and right-turning motor flow were both subject to Poisson distributions. Nonmotor flow only contained bicycles, the bicycle flow was only 
in one line, and the service time followed a negative exponential distribution [6]. Poisson distribution is applicable to the random vehicle arriving, generally with flow rate less than $500 \mathrm{veh} / \mathrm{h}$ per lane. As urban road traffic is more and more congested while Poisson distribution is just applicable to free flow, it is hard to meet the actual traffic circumstances. As a consequence, Poisson distribution will be invalid when the flow rate is more than $500 \mathrm{veh} / \mathrm{h}$ per lane. Thus, it limits the application of the model to a large extent. Conversely, Erlang distribution, as a general distribution, has a high applicability to all traffic conditions.

Accordingly, this paper aims to establish the model of the travel time of right-turning vehicles on secondarystreet at unsignalized intersections in congested urban traffic condition. This provides theoretical support for improving the traffic management, intersection control, designation, evaluation, and ITS application.

This paper is organized as follows. The first part gives a general introduction. The second part presents the model establishment methodology. Then, Section 3 takes an intersection as a numerical example to validate the models. In Section 4 , the model sensitivity is analyzed. The final section then concludes the paper and gives suggestions for further study.

\section{Model Establishment}

2.1. Research Conditions Settings. Convenient for the study, the following assumptions were made in this paper.

(1) The following distribution models are usually used to describe traffic flow headway: negative exponential distribution, Weibull distribution, and Erlang distribution. The negative exponential distribution can be applied to the situation that vehicles arrive at random, generally in which the flow rate per hour per lane is less than $500 \mathrm{veh} / \mathrm{h}$. Weibull distribution has a broader application range. Erlang distribution is also a general probability distribution of headway. Erlang distribution could be obtained by calculating the parameter $l$. Considering the applicability and conveniences of calibration, Erlang distribution is usually used to describe headway of major-street traffic flow. The negative exponential distribution is more suitable when the right-turning flow on the secondary street is not large.

(2) The vehicles on secondary street follow the right-in and right-out principle, and pedestrian is prohibited to cross, which is the management and control strategy of the unsignalized intersection.

(3) Drivers abide by the principle of the major-street priority strictly, and there is no grab-line phenomenon.

(4) In this research, the gap theory is adopted. The gap theory can be described as follows: at an unsignalized intersection, vehicles on the major street have the priority to cross, while the secondary-street vehicles have to wait for gaps long enough to cross.

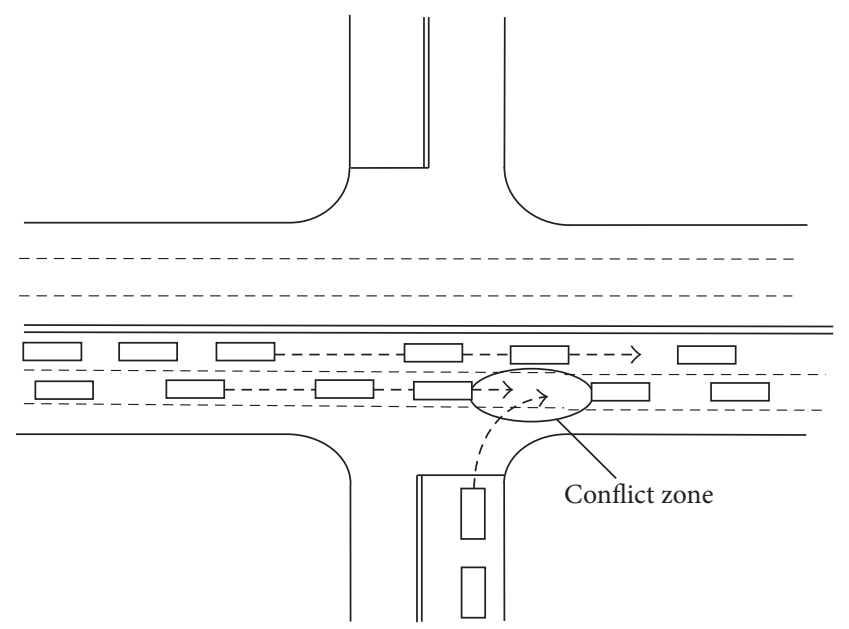

FIGURE 1: Service desk at unsignalized intersection.

Therefore, the maximum flow rate of the secondarystreet may be concluded by calculating the number of gaps provided by the major-street flow. The gap theory is used under the situation that secondarystreet vehicles pass through the major-street flow perpendicularly at intersections. However, the actual right-turning movements at intersections do not cross the counter flow in perpendicularity. In this case, it is assumed that the right-turning movement crossed them perpendicularly.

(5) Queue theory: a system subjects to $M / G / 1$, that is, vehicles arrival follows Poisson distribution, service time follows random distribution, and a single reception desk obeys the rule that the first comer should be served first under the condition that right-turning vehicles are waiting for services in the queue system. The service time is not definite, and there is only one right-turning lane.

2.2. Model Establishment. Based on the above research conditions settings, the conflict zone between right-turning vehicles on the secondary-street and opposing through vehicles on the major street can be seen as a single service desk as shown in Figure 1. The secondary-street right-turning vehicles receive service, and headway of opposing through flow provides service. As mentioned in the above assumptions, arrival of right-turning flow follows Poisson distribution, the service time follows Poisson distribution, and a single reception desk system obeys the rule of first comer to be served first, namely, the $\mathrm{M} / \mathrm{M} / 1$ system.

In this research, the critical accepted headway of rightturning vehicles is $\tau_{c}$, headway of the major-street through vehicles is $h$, and the following headway of right-turning vehicles is $h_{f}$. Considering that there is a vehicle queue on secondary-street, then we will have different conditions: when $h$ is less than $\tau_{c}$, no right-turning vehicles can merge into major street; when $h$ is between $\tau_{c}$ and $\tau_{c}+h_{f}$, only one vehicle can cross; when $h$ is between $\tau_{c}+h_{f}$ and $\tau_{c}+2 h_{f}$, two vehicles may merge into major street; when $\tau_{c}+(n-1) h_{f} \leq$ 
TABle 1: Probability of headway.

\begin{tabular}{|c|c|c|}
\hline Headway & Vehicles number $/ i$ & Probability $/ P_{i}$ \\
\hline$\tau_{c} \leq h<\tau_{c}+h_{f}$ & 1 & $\sum_{i=0}^{l-1}\left(\lambda l \tau_{c}\right)^{i} \frac{e^{-\lambda \tau_{c}}}{i !}-\sum_{i=0}^{l-1}\left(\lambda l\left(\tau_{c}+h_{f}\right)\right)^{i} \frac{e^{-\lambda\left(\tau_{c}+h_{f}\right)}}{i !}$ \\
\hline$\tau_{c}+h_{f} \leq h<\tau_{c}+2 h_{f}$ & 2 & $\sum_{i=0}^{l-1}\left(\lambda l\left(\tau_{c}+h_{f}\right)\right)^{i} \frac{e^{-\lambda\left(\tau_{c}+h_{f}\right)}}{i !}-\sum_{i=0}^{l-1}\left(\lambda l\left(\tau_{c}+2 h_{f}\right)\right)^{i} \frac{e^{-\lambda\left(\tau_{c}+2 h_{f}\right)}}{i !}$ \\
\hline$\tau_{c}+2 h_{f} \leq h<\tau_{c}+3 h_{f}$ & 3 & $\sum_{i=0}^{l-1}\left(\lambda l\left(\tau_{c}+2 h_{f}\right)\right)^{i} \frac{e^{-\lambda\left(\tau_{c}+2 h_{f}\right)}}{i !}-\sum_{i=0}^{l-1}\left(\lambda l\left(\tau_{c}+3 h_{f}\right)\right)^{i} \frac{e^{-\lambda\left(\tau_{c}+3 h_{f}\right)}}{i !}$ \\
\hline$\vdots$ & $\vdots$ & $\vdots$ \\
\hline$\tau_{c}+(n-1) h_{f} \leq h<\tau_{c}+n h_{f}$ & $n$ & $\sum_{i=0}^{l-1}\left(\lambda l\left(\tau_{c}+(n-1) h_{f}\right)\right)^{i} \frac{e^{-\lambda\left(\tau_{c}+(n-1) h_{f}\right)}}{i !}-\sum_{i=0}^{l-1}\left(\lambda l\left(\tau_{c}+n h_{f}\right)\right)^{i} \frac{e^{-\lambda\left(\tau_{c}+n h_{f}\right)}}{i !}$ \\
\hline
\end{tabular}

$h<\tau_{c}+n h_{f}, n$ vehicles may merge into major-street. The headway of major-street flow follows Erlang distribution, and it can be written as

$$
P(h \geq t)=\sum_{i=0}^{l-1}(\lambda l t)^{i} \frac{e^{-\lambda t}}{i !},
$$

where $\lambda$ is the arriving rate of major-street vehicles, veh/s; $l$ is the distribution parameter, if $l=1$, the formula above could be simplified as negative exponential distribution; while $l=$ $\infty$, headway will follow uniform distribution. In practice, $l$ could be determined by $m$ and $S^{2}$ with rounding-off method. The formula may be expressed as

$$
l=\operatorname{int}\left(\frac{m^{2}}{S^{2}}\right)
$$

where $m$ is the observed average headway of major-street flow, s; $S^{2}$ is the variance of observed headway of major-street flow

$$
P(h \geq t)=\sum_{i=0}^{l-1}(\lambda l t)^{i} \frac{e^{-\lambda t}}{i !} .
$$

Consequently, the probability of different headway on major street can be expressed as

$$
\begin{aligned}
P_{i} & =P\left(\tau_{c}+(i-1) h_{f} \leq h \leq \tau_{c}+i h_{f}\right) \\
& =P\left(h \geq \tau_{c}+(i-1) h_{f}\right)-P\left(h \geq \tau_{c}+i h_{f}\right),
\end{aligned}
$$

where $P_{i}$ is the probability of headway on the major street that allows $i$ vehicles on the secondary street to merge into majorstreet flow. The probability of different headway is shown in Table 1.

The number of right-turning vehicles may merge into major-street flow per unit time and can be expressed as

$$
\begin{gathered}
N=\sum_{i=1}^{n} i \cdot \lambda \cdot P_{i} \\
N=\sum_{m=0}^{n-1} \sum_{i=0}^{l-1} \lambda\left(\lambda l\left(\tau_{c}+m h_{f}\right)\right)^{i} \frac{e^{-\lambda\left(\tau_{c}+m h_{f}\right)}}{i !} \\
-n \sum \lambda\left(\lambda l\left(\tau_{c}+n h_{f}\right)\right)^{i} \frac{e^{-\lambda\left(\tau_{c}+n h_{f}\right)}}{i !}
\end{gathered}
$$

where $N$ is the number of right-turning vehicles and may merge into major-street flow per unit time, veh/s; $i$ is the number of right-turning vehicles and may merge into majorstreet flow in one headway; $P_{i}$ is the probability of the headway and may provide $i$ right-turning vehicles to merge into major-street flow; the other parameters have the same meanings as previously mentioned.

From the M/G/1 queue system, the average travel time of each vehicle in the queue is

$$
T=\frac{\rho^{2}+\lambda_{1}^{2} \delta^{2}}{2 \lambda_{1}(1-\rho)}+\frac{1}{\mu},
$$

where $\lambda_{1}$ is the average arrival rate of right-turning flow, veh/s; $\mu$ is the service rate of right-turning flow, $\mu=N$, $\mathrm{veh} / \mathrm{s} ; \delta^{2}$ is the variance of vehicles service time; $\rho$ is the service intensity or traffic intensity, $\rho=\lambda_{1} / \mu$, which reflects the traffic conditions. If $\rho<1$, it means that the flow is stable, and each traffic condition will be repeated with a certain probability. If $\rho \geq 1$, the flow is unstable, and queue will become longer and longer.

When $\delta^{2}=0$, service time follows uniform distribution, which may be expressed as

$$
T=\frac{\rho^{2}}{2 \lambda_{1}(1-\rho)}+\frac{1}{\mu} .
$$

When $\delta^{2}=1 / \mu^{2}$, service time is subject to negative exponential distribution, which can be written as

$$
T=\frac{\rho^{2}}{\lambda_{1}(1-\rho)}+\frac{1}{\mu} .
$$

2.3. Existing Model. Most of the present researches assume that traffic flow arrival is subject to Poisson distribution, and the queue system is an $\mathrm{M} / \mathrm{M} / 1$ one. The corresponding models are as follows.

The service rate of right-turning flow may be expressed as

$$
\mu=\frac{\lambda e^{-\lambda \tau_{c}}}{1-e^{-\lambda h_{f}}} .
$$




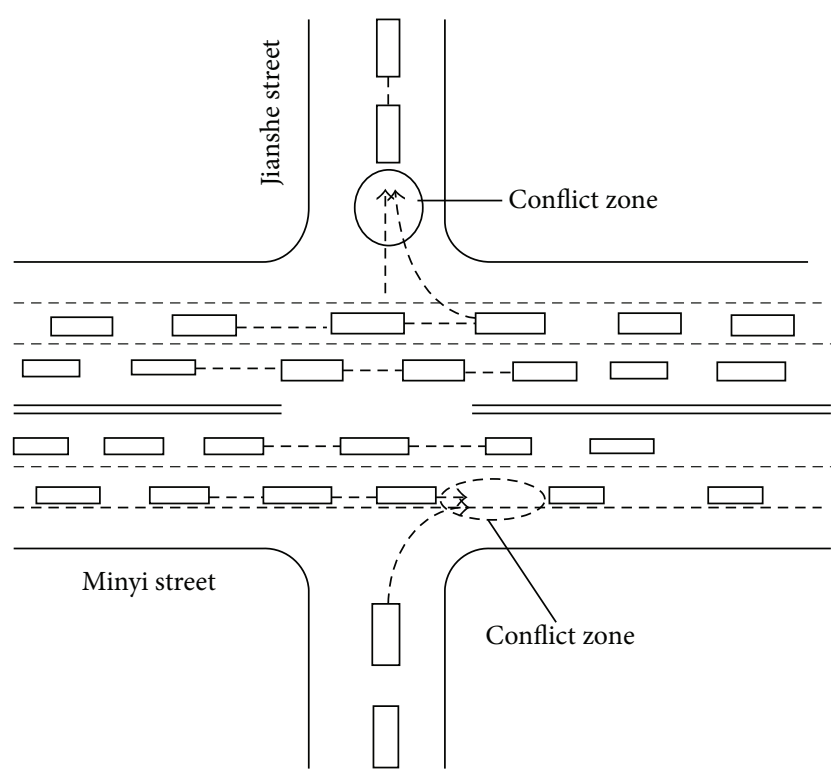

FIGURE 2: The sketch of study case.

The travel time of right-turning vehicles merging into the main-street flow can be written as

$$
T=\frac{1}{\mu-\lambda_{1}}=\frac{1}{\left(\lambda e^{-\lambda \tau_{c}} /\left(1-e^{-\lambda h_{f}}\right)\right)-\lambda_{1}} .
$$

The parameters have the same meanings as previously mentioned.

\section{Models Validation}

There are some differences between the application premise of gap theory and the research conditions in this paper. For example, the merging of right-turning vehicles into the major-street flow is not perpendicular, and the drivers do not strictly abide by the rule of major-street priority, especially when the right-turning flow rate is a bit large. Therefore, there still exists the phenomenon of grabbing line. It can be seen from the above that there exist some objective conditions that do not correspond with the practical situations. Thus, it is necessary to validate the models.

A real intersection of Harbin in China was selected to verify the accuracy of the above model based on Erlang distribution (Model-I) and the one based on Poisson distribution (Model-II). This unsignalized intersection lies in Nangang district of Harbin, and its geometric condition is shown in Figure 2. We conducted field observation in both rush and nonrush hours for one week. The following parameters were observed: flow rate and following headway of the majorstreet through vehicles, arrival rate and following headway of the secondary-street right-turning vehicles, and the time consumed to merge into the major-street flow and the critical headway accepted by right-turning vehicles. According to the field observation, critical headway $\tau_{c}$ evaluated by maximum

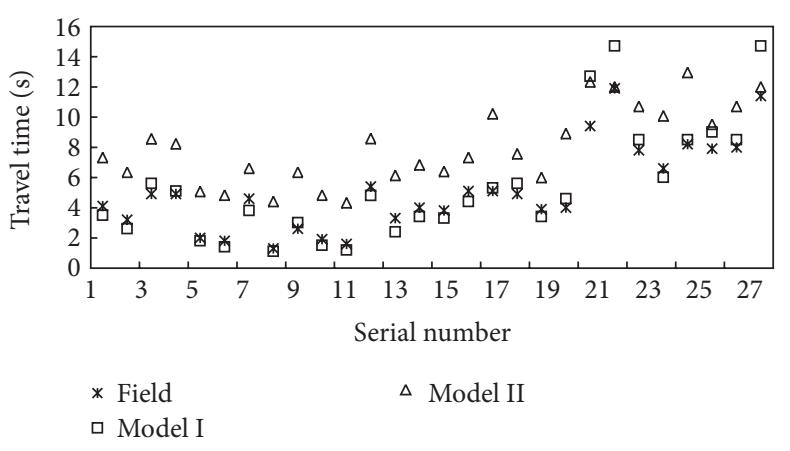

FIGURE 3: Model validation curve.

likelihood estimation is $3.9 \mathrm{~s}$, and $h_{f}$ is $2.1 \mathrm{~s}$. The above observation data and the results are applied to (8) and (10), and the results are shown in Table 2. The comparison curves of Model-I, Model-II, and the field observation data are shown in Figure 3.

It can be seen from the results that Model-I has better performance than Model-II, and most times the relative errors of Model-I are less than $15 \%$, with the maximum one $35.11 \%$. The higher accuracy is owing to the reasonable selected headway distribution. The main distinctions between Model-I and Model-II are the distribution models of the major-street traffic flow. Erlang distribution and Poisson distribution are used in Model-I and Model-II, respectively. It is well known that Poisson distributions are applicable to the random vehicle arriving, generally with flow rate less than $500 \mathrm{veh} / \mathrm{h}$ per lane. As a matter of fact, urban road traffic is more and more congested, while Poisson distribution is just applicable to free flow, and it is hard to meet the actual traffic circumstances. As a result, the Poisson distribution will be invalid when the flow rate is more than $500 \mathrm{veh} / \mathrm{h}$ per lane. Thus, it limits the application of Model-II. Conversely, Erlang distribution, as a general distribution, has a high applicability to all traffic conditions. Consequently, Model-I has better performance than Model-II.

The relative error of Model-I is relevant to the flow rate, indicating that the relative error shows an obvious rising trend with the increase of the flow rate. For instance, the most relative error is more than $15 \%$, and the actual travel time is shorter than the theoretical value, while the flow rate of the major-street speeds up to $0.4 \mathrm{veh} / \mathrm{s}$, and the flow rate of the right-turning vehicles reaches $0.04 \mathrm{veh} / \mathrm{s}$. The reasons are as follows: with the increase of the rightturning vehicles flow rate, the number of headway long enough for right-turning vehicles to merge into major street decreases. When the flow rate of right-turning vehicles is increasing at the moment, there would be a formation of queues. Therefore, the right-turning vehicles may go after the front car to grab into the major street, and then the rightturning travel time will reduce, and the relative error will increase. 
TABLE 2: Model validation data.

\begin{tabular}{|c|c|c|c|c|c|c|c|c|c|c|}
\hline \multirow{2}{*}{ Serial number } & \multirow{2}{*}{$\tau_{c}(\mathrm{~s})$} & \multirow{2}{*}{$h_{f}(\mathrm{~s})$} & \multirow{2}{*}{$l$} & \multirow{2}{*}{$\lambda_{1}(\mathrm{veh} / \mathrm{s})$} & \multirow{2}{*}{$\lambda(\mathrm{veh} / \mathrm{s})$} & \multirow{2}{*}{ Field (s) } & \multicolumn{2}{|c|}{ Model-I } & \multicolumn{2}{|c|}{ Model-II } \\
\hline & & & & & & & Theoretical (s) & Relative error (\%) & Theoretical (s) & Relative error (\%) \\
\hline 1 & 3.9 & 2.1 & 2 & 0.03 & 0.36 & 4.1 & 3.5 & 14.63 & 7.3 & 78.44 \\
\hline 2 & 3.9 & 2.1 & 2 & 0.03 & 0.32 & 3.2 & 2.6 & 18.75 & 6.3 & 98.11 \\
\hline 3 & 3.9 & 2.1 & 3 & 0.04 & 0.38 & 4.9 & 5.6 & 14.29 & 8.5 & 74.39 \\
\hline 4 & 3.9 & 2.1 & 3 & 0.04 & 0.37 & 4.9 & 5.1 & 4.08 & 8.2 & 67.57 \\
\hline 5 & 3.9 & 2.1 & 2 & 0.02 & 0.27 & 2 & 1.8 & 10.00 & 5.1 & 152.95 \\
\hline 6 & 3.9 & 2.1 & 2 & 0.03 & 0.24 & 1.8 & 1.4 & 22.22 & 4.8 & 167.40 \\
\hline 7 & 3.9 & 2.1 & 3 & 0.02 & 0.35 & 4.6 & 3.8 & 17.39 & 6.6 & 43.28 \\
\hline 8 & 3.9 & 2.1 & 2 & 0.04 & 0.2 & 1.3 & 1.1 & 15.38 & 4.4 & 238.38 \\
\hline 9 & 3.9 & 2.1 & 3 & 0.03 & 0.32 & 2.6 & 3.0 & 15.38 & 6.3 & 143.82 \\
\hline 10 & 3.9 & 2.1 & 3 & 0.03 & 0.24 & 1.9 & 1.5 & 21.05 & 4.8 & 153.33 \\
\hline 11 & 3.9 & 2.1 & 3 & 0.02 & 0.22 & 1.6 & 1.2 & 25.00 & 4.3 & 169.25 \\
\hline 12 & 3.9 & 2.1 & 3 & 0.05 & 0.36 & 5.4 & 4.8 & 11.11 & 8.6 & 58.70 \\
\hline 13 & 3.9 & 2.1 & 2 & 0.03 & 0.31 & 3.3 & 2.4 & 27.27 & 6.1 & 85.46 \\
\hline 14 & 3.9 & 2.1 & 2 & 0.02 & 0.36 & 4 & 3.4 & 15.00 & 6.8 & 70.43 \\
\hline 15 & 3.9 & 2.1 & 2 & 0.01 & 0.36 & 3.8 & 3.3 & 13.16 & 6.4 & 67.95 \\
\hline 16 & 3.9 & 2.1 & 3 & 0.03 & 0.36 & 5.1 & 4.4 & 13.73 & 7.3 & 43.45 \\
\hline 17 & 3.9 & 2.1 & 2 & 0.05 & 0.40 & 5.1 & 5.3 & 3.92 & 10.2 & 100.27 \\
\hline 18 & 3.9 & 2.1 & 3 & 0.02 & 0.39 & 4.9 & 5.6 & 14.29 & 7.6 & 54.14 \\
\hline 19 & 3.9 & 2.1 & 3 & 0.01 & 0.34 & 3.9 & 3.4 & 12.82 & 6.0 & 53.62 \\
\hline 20 & 3.9 & 2.1 & 2 & 0.04 & 0.39 & 4 & 4.6 & 15.00 & 8.9 & 122.42 \\
\hline 21 & 3.9 & 2.1 & 3 & 0.05 & 0.44 & 9.4 & 12.7 & 35.11 & 12.3 & 31.06 \\
\hline 22 & 3.9 & 2.1 & 3 & 0.04 & 0.46 & 11.9 & 14.7 & 23.53 & 12.0 & 0.64 \\
\hline 23 & 3.9 & 2.1 & 3 & 0.05 & 0.41 & 7.8 & 8.5 & 8.97 & 10.7 & 37.06 \\
\hline 24 & 3.9 & 2.1 & 2 & 0.04 & 0.42 & 6.6 & 6.0 & 9.09 & 10.1 & 52.59 \\
\hline 25 & 3.9 & 2.1 & 2 & 0.05 & 0.45 & 8.2 & 8.5 & 3.66 & 12.9 & 57.81 \\
\hline 26 & 3.9 & 2.1 & 3 & 0.03 & 0.43 & 7.9 & 9.0 & 13.92 & 9.5 & 20.35 \\
\hline 27 & 3.9 & 2.1 & 3 & 0.05 & 0.41 & 8 & 8.5 & 6.25 & 10.7 & 33.63 \\
\hline 28 & 3.9 & 2.1 & 3 & 0.04 & 0.46 & 11.4 & 14.7 & 28.95 & 12.0 & 5.05 \\
\hline
\end{tabular}

\section{Sensitivity Analyses}

It is proved in the above section that the model established in this article has an overall better performance. The relationship between parameters and travel time was explored in this section. Specifically speaking, these variables include majorstreet through flow rate and secondary-street right-turning flow rate.

The influence of the variables is shown in Figure 4. To study the influence of major-street through flow rate and secondary-street right-turning flow rate, the travel times at different flow rates are shown in Figure 4. The trends in this figure indicate the following, (1) Right-turning vehicles travel times increase with the rising of the right-turning flow rate and the conflicting through flow rate. (2) When the conflicting through flow rate is low, the right-turning flow rate has a slight effect on right-turning vehicles travel times. With the increase of through flow rate, the rightturning flow rate would have a more obvious effect on travel time. Simultaneously, the threshold is about $0.30 \mathrm{veh} / \mathrm{s}$. These findings indicate two facts: the larger the number of the opposing through vehicles is, the less acceptable the headway

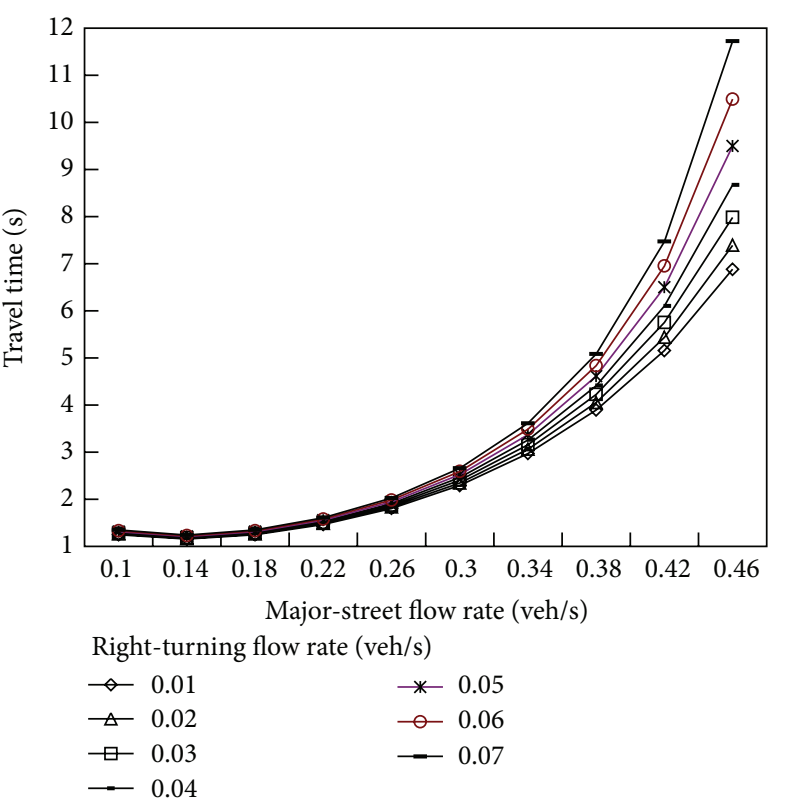

FIGURE 4: Influence of flow rate on right-turning vehicles travel time. 
would be; the larger the right-turning flow rate is, the longer the queue and the longer the travel time would be.

\section{Conclusions}

(1) The travel time model based on Erlang distribution for major-street flow and M/G/1 queue system has a better applicability. The relative error has no obvious linear relationship with flow rate, and the error would still be stable, until the flow rate of the major street speeds up to $0.4 \mathrm{veh} / \mathrm{s}$ and the right-turning vehicles flow rate reaches $0.04 \mathrm{veh} / \mathrm{s}$. Meanwhile, when the right-turning flow rate and major-street flow rate increase, the error also increases. This result shows the applicability of the model.

(2) The factors that have significant influence on the travel time are major-street flow rate and rightturning vehicles arrival rate. The travel time increases with the growth of them. In fact, there are other factors that have influence on the travel time, such as the intersection control pattern. Whether it is signalized or unsignalized, or it is interrupted by the pedestrian and the vehicles compositions or not, the intersection control pattern will always affect the travel time. Up to now, there is no such research on intersection control pattern, which we should spare no efforts to do within the coming future.

\section{Acknowledgments}

This research was supported by China Postdoctoral Science Foundation (2011M500676), National Education Ministry Humanities and Social Sciences Foundation (12YJCZH097), Heilongjiang Institute of Technology Doctoral Science Foundation (2011BJ05) and Technology Research and Development Program of Shandong (2012G0020129). The authors are also grateful to the anonymous referees for their helpful comments and constructive suggestions on an earlier version of the paper.

\section{References}

[1] S. M. Madanat, M. J. Cassidy, and M. H. Wang, "Probabilistic delay model at stop-controlled intersection," Journal of Transportation Engineering, vol. 120, no. 1, pp. 21-36, 1994.

[2] M. A. Qureshi and L. D. Han, "Delay model for right-turn lanes at signalized intersections with uniform arrivals and right turns on red," Transportation Research Record, vol. 1776, pp. 143-150, 2001.

[3] G. Abu-Lebdeh, R. F. Benekohal, and B. Al-Omari, "Models for right-turn-on-red and their effects on intersection delay," Transportation Research Record, vol. 1572, pp. 131-139, 1997.

[4] B. Hoeschen, D. Bullock, and M. Schlappi, "Estimating intersection control delay using large data sets of travel time from a global positioning system," Transportation Research Record, vol. 1917, pp. 18-27, 2005.

[5] T. Hagiwara, H. Hamaoka, T. Yaegashi, K. Miki, I. Ohshima, and M. Naito, "Estimation of time lag between right-turning vehicles and pedestrians approaching from the right side," Transportation Research Record, vol. 2069, pp. 65-76, 2008.

[6] C. Y. Liang, C. G. Wang, Z. Shen, and D. H. Wang, "Calculation method of travel time of right-turn vehicle at motor- and nonmotor-vehicle mixed traffic intersection," Journal of Jilin University, vol. 37, no. 5, pp. 1053-1057, 2007.

[7] R. L. Smith and T. Walsh, "Safety impacts of bicycle lanes," Transportation Research Record, vol. 1168, pp. 49-56, 1988.

[8] H. Liu, H. J. Van Zuylen, H. Van Lint, Y. Chen, and K. Zhang, "Prediction of urban travel times with intersection delays," in Proceedings of the 8th International IEEE Conference on Intelligent Transportation Systems (ITSC '05), pp. 1062-1067, September 2005.

[9] X. G. Ban, P. Hao, and Z. B. Sun, "Real time queue length estimation for signalized intersections using travel times from mobile sensors," Transportation Research C, vol. 19, pp. 11331156, 2011.

[10] K. Ahmed, "Evaluation of low cost technique "indirect right turn" to reduce congestion at urbanized signalized intersection in developing countries," in Proceedings of the 6th International Symposium on Highway Capacity and Quality of Service (ISHC '11), vol. 16, pp. 568-577, July 2011.

[11] C. Lu, F. Zhao, and M. Hadi, "A travel time estimation method for planning models considering signalized intersections," in Proceedings of the 10th International Conference of Chinese Transportation Professionals-Integrated Transportation Systems: Green, Intelligent, Reliable (ICCTP '10), pp. 1993-2000, August 2010.

[12] J. A. Bonneson, "Delay to major-street through vehicles due to right-turn activity," Transportation Research A, vol. 32, no. 2, pp. 139-148, 1998.

[13] Y. Wang and N. L. Nihan, "Estimating the risk of collisions between bicycles and motor vehicles at signalized intersections," Accident Analysis and Prevention, vol. 36, no. 3, pp. 313-321, 2004.

[14] C. Quiroga, M. Perez, and S. Venglar, "Tool for measuring travel time and delay on arterial corridors," in Proceedings of the 7th International Conference on: Applications of Advanced Technology in Transportation, pp. 600-607, August 2002.

[15] J. Q. Leng, Y. Q. Feng, J. Zhai, L. Bao, and Y. He, “Travel time model of left-turning vehicles at signalized intersection," Mathematical Problem in Engineering, vol. 2010, Article ID 473847, 10 pages, 2012. 


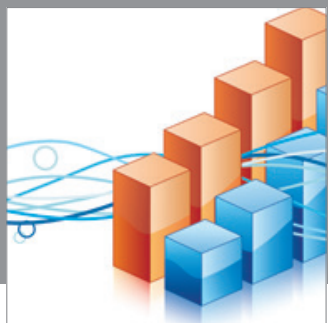

Advances in

Operations Research

mansans

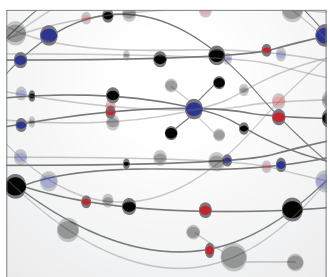

The Scientific World Journal
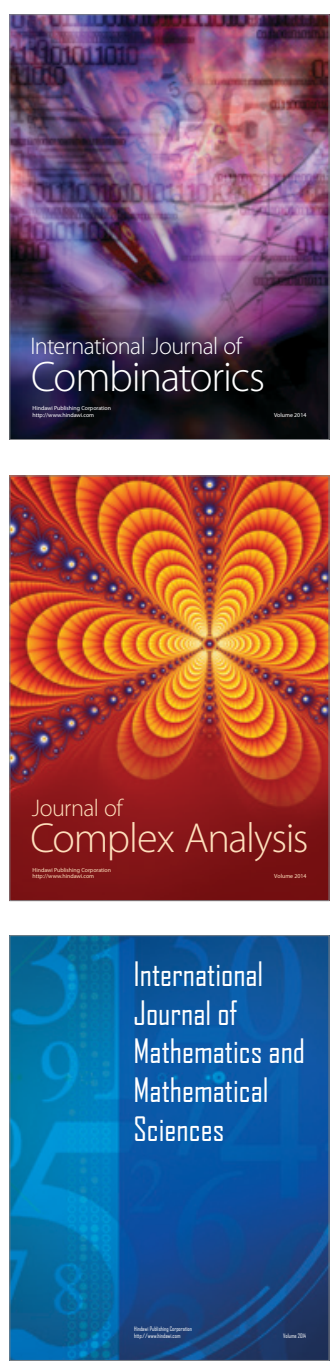
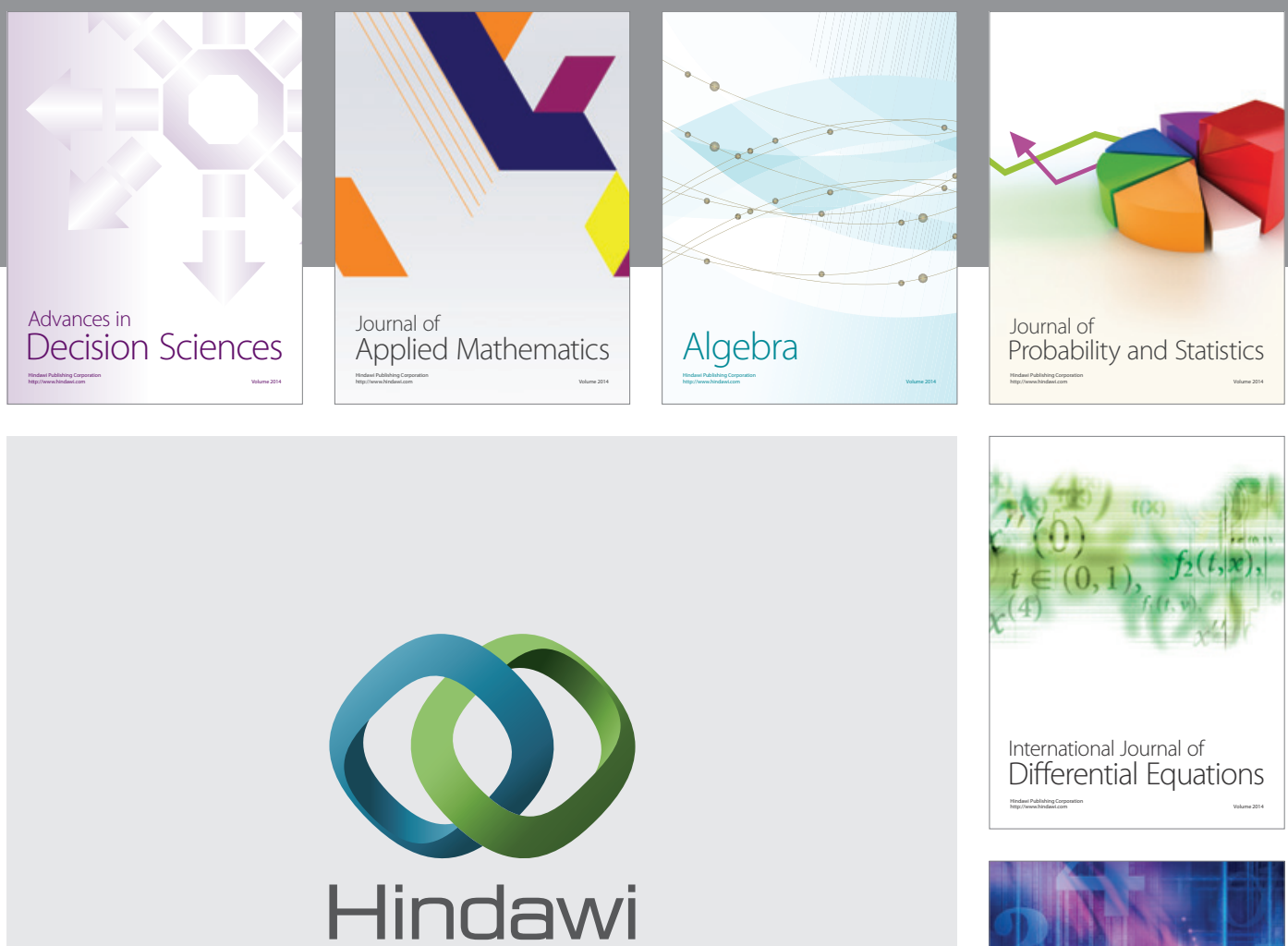

Submit your manuscripts at http://www.hindawi.com
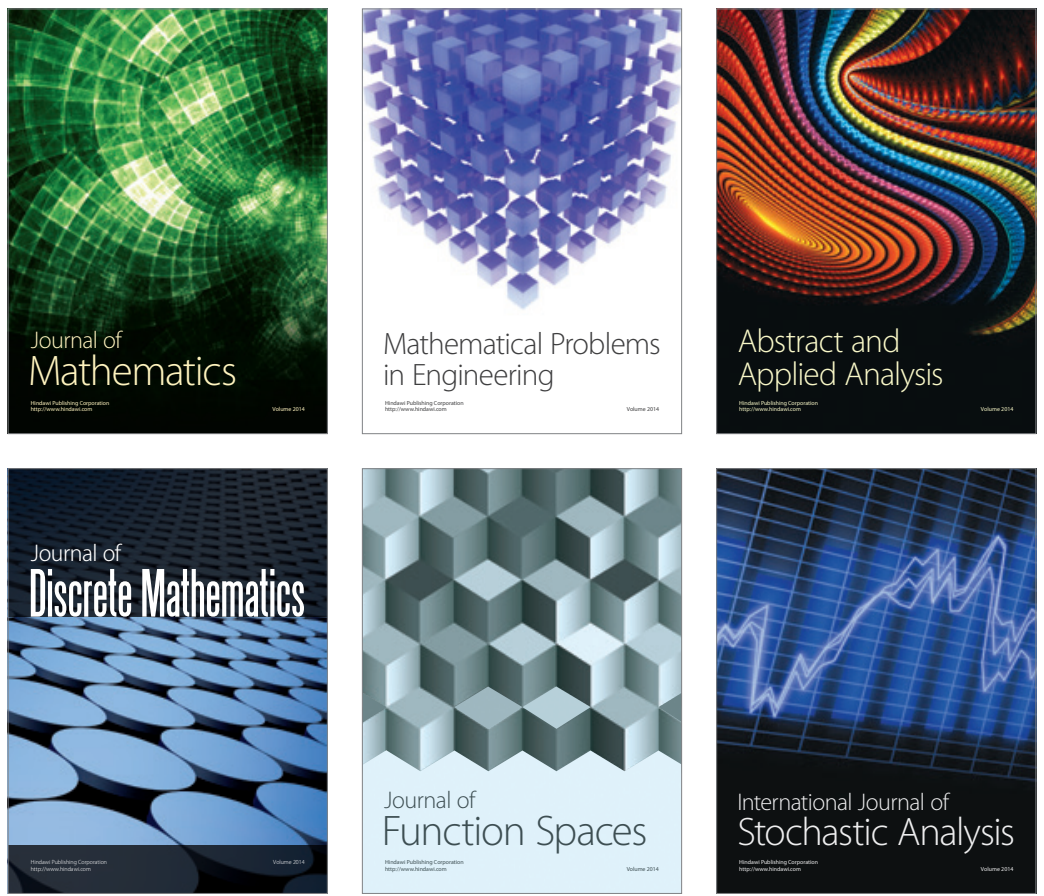

Journal of

Function Spaces

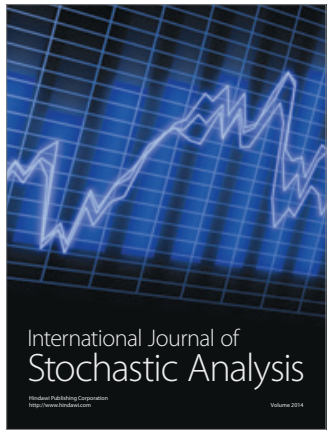

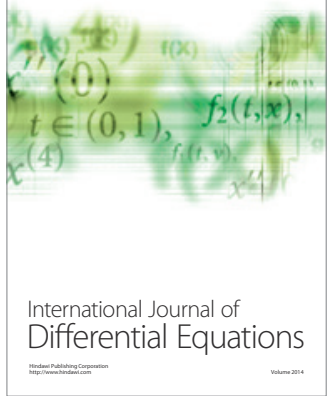
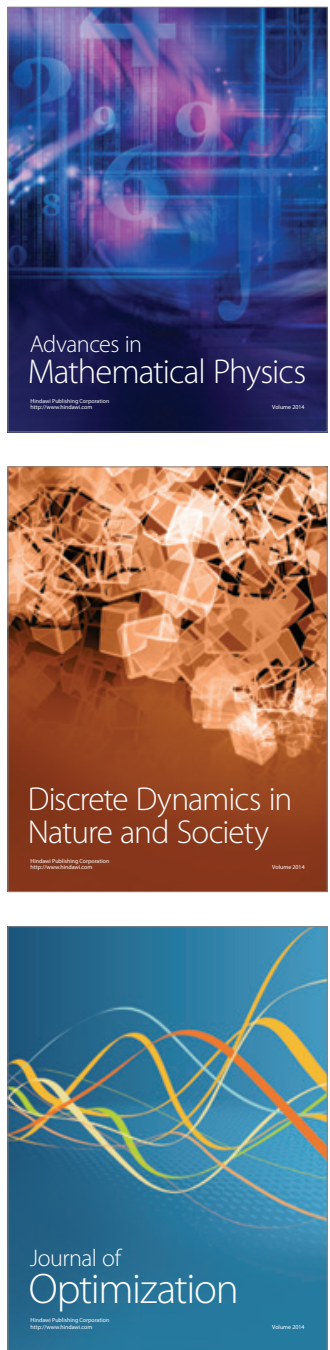